\title{
Population structure of bigeye tuna (Thunnus obesus) in the Indian Ocean inferred from mitochondrial DNA
}

\author{
Hsin-Chieh Chiang ${ }^{\mathrm{a}}$, Chien-Chung Hsu ${ }^{\mathrm{a}}$, Georgiana Cho-Chen $\mathrm{Wu}^{\mathrm{b}}$, \\ Shui-Kai Chang ${ }^{c}$, Hsi-Yuan Yang ${ }^{b}$, \\ a Institute of Oceanography, National Taiwan University, Taipei, Taiwan, ROC \\ ${ }^{\mathrm{b}}$ Institute of Molecular and Cellular Biology, National Taiwan University, Taipei, Taiwan, ROC \\ ${ }^{\mathrm{c}}$ Institute of Marine Affairs, National Sun Yat-Sen University, Kaohsiung, Taiwan, ROC \\ Received 14 March 2007; received in revised form 6 November 2007; accepted 6 November 2007
}

\begin{abstract}
Population structure of bigeye tuna (Thunnus obesus) in the Indian Ocean, Western Pacific Ocean and Eastern Atlantic Ocean were investigated using mitochondrial (mt) DNA sequence data. A total of 380 specimens were sampled from four regions in the Indian Ocean (Cocos Islands, Southeastern Indian Ocean, Southwestern Indian Ocean and Seychelles), and one region each from the Atlantic (Guinea) and the Western Pacific Oceans, respectively. The reconstructed neighbor-joining phylogeny based on the first hypervariable region (HVR-1) of the mitochondrial control region sequence data showed that haplotypes from the Indian and the Western Pacific Oceans could be grouped into two clades (Clades I and III), whereas in the Atlantic Ocean, two divergent clades (Clades I and II) coexisted. A single stock of bigeye tuna in the Indian Ocean was supported by hierarchical AMOVA tests and pairwise $\Phi_{\mathrm{ST}}$ analyses. Clade I was the dominant population in the Indian and the Western Pacific Oceans which consisted of more than $96 \%$ of the specimens and Clade II was a specific group exclusively restricted to the Atlantic Ocean which made up $77 \%$ of its specimens. A new minor Clade, Clade III was discovered in the Indian and the Western Pacific Ocean. Overall, these analyses indicated that bigeye tuna of the Indian Ocean constituted a single panmictic population.
\end{abstract}

(C) 2007 Elsevier B.V. All rights reserved.

Keywords: Bigeye tuna (Thunnus obesus); Mitochondrial DNA; Control region; Population structure; Western Pacific Ocean; Indian Ocean

\section{Introduction}

Bigeye tuna (Thunnus obesus Lowe, 1839) is a cosmopolitan, highly migratory pelagic fish with important commercial value. The Second World Meeting on Bigeye Tuna has pointed out the increasing concerns on the bigeye tuna stock status due to worldwide overfishing in recent years (ICCAT, 2005). A better understanding of its population structure is important to an effective fisheries management.

At present, our knowledge on the bigeye tuna population structure is developing and progressing. Previous studies revealed that the global bigeye tuna population consisted of two clades (Alvarado-Bremer et al., 1998; Chow et al., 2000; Appleyard et al., 2002; Durand et al., 2005; Martínez et al., 2006; Chiang et al., 2006). Both clades existed in all three oceans

\footnotetext{
* Corresponding author. Tel.: +886 233662479 ; fax: +886233662478 . E-mail address: hyhy@ntu.edu.tw (H.-Y. Yang).
}

with significantly different distribution frequencies between the Atlantic and the Indo-Pacific Oceans. Clade I was the dominant clade in the Indo-Pacific Ocean, contributing to $90 \%$ of its population, while Clade II was the main clade of the Atlantic Ocean, making up $73 \%$ of its population (Alvarado-Bremer et al., 1998). The existence of two clades of bigeye tuna was later corroborated by PCR-RFLP analyses of two mtDNA segments, the control region and a segment (ATCO) flanking the ATPase and cytochrome oxidase III genes (Chow et al., 2000). Only two genotypes ( $\alpha$ and $\beta$ ) were detected following RsaI digestion of the ATCO segment. The $\alpha$ type was dominant in the Atlantic Ocean (i.e., 178 out of 244 samples), and all but one of the 195 Indo-Pacific samples were $\beta$ type. Moreover, bigeye tuna samples of the Indian Ocean were examined for variations at seven microsatellite loci and at the ATCO region by PCRRFLP analyses (Appleyard et al., 2002). The results indicated that the genetic differentiation was non-significant between samples collected from the Eastern and the Western Indian Oceans. Appleyard et al. detected two haplotypes, BET1 (similar to $\alpha$ 
type, Chow et al., 2000) and BET2 (similar to $\beta$ type, Chow et al., 2000) which were distributed mainly in the Atlantic Ocean and the Indo-Pacific Ocean, respectively. It is interesting to note that while no BET1 haplotype was found in the Eastern Indian Ocean, 4 out of $119(\sim 3 \%)$ individuals from the Western Indian Ocean belonged to this group. Recently, the genetic differentiation between the Atlantic and the Indo-Pacific mitochondrial lineages was further confirmed by the characterization of four nuclear DNA loci (Durand et al., 2005). The results indicated unidirectional gene flow of the bigeye tuna populations from the Indo-Pacific Ocean to the Atlantic and their admixture off southern Africa. In 2006, Martínez et al. first used the sequence data of the first hypervariable region (HVR-1) of the mitochondrial control region to examine the genetic variability of bigeye tuna in the Atlantic Ocean. The results also indicated that two divergent mitochondrial lineages existed in the Atlantic bigeye tuna population and suggested present unidirectional gene flow from the Indo-Pacific into the Atlantic Ocean. Furthermore, sequence data analysis revealed no existence of Clade II in both the Eastern Pacific Ocean and Seychelles of the Indian Ocean. Recently, through sequence analysis of mtDNA HVR-1, Chiang et al. (2006) showed that bigeye tuna over the Western Pacific Ocean constituted a single panmictic population.

Although the Indian Ocean is one of the largest fishing grounds of bigeye tuna, only few studies focused on the bigeye tuna population structure in this region. According to the results of PCR-RFLP analysis, few individuals from the Indian Ocean were grouped into Clade II of the Atlantic Ocean (AlvaradoBremer et al., 1998; $\alpha$ type, Chow et al., 2000; BET1 haplotype, Appleyard et al., 2002). However, recent PCR-sequencing analyses showed that none of the Seychelles samples belonged to the major Atlantic clade (Clade II, Martínez et al., 2006). Putting into consideration that PCR sequencing seemed to be more effective than the RFLP approach (Buonnacorsi et al., 2001) and that this procedure has not been performed on the bigeye tuna population genetic structure of the whole Indian Ocean, in this study we analyzed the HVR-1 sequences of 380 bigeye tuna specimens from the Indian, Western Pacific and Atlantic Oceans to further investigate its population structure and phylogenetic information.

\section{Materials and methods}

\subsection{Sampling and DNA sequencing}

Bigeye tuna samples with exact location information from four Indian Ocean regions $(n=223)$ and from Guinea of the Atlantic Ocean $(n=57)$ were collected by scientific observers from commercial fishing vessels during 2000-2004 (Fig. 1 and Table 1). Bigeye tuna samples from the Western Pacific Ocean ( $n=100)$ were also included (Chiang et al., 2006). Muscle tissue specimens were fixed in $95 \%$ ethanol and frozen at $-20^{\circ} \mathrm{C}$ until DNA extraction. DNA extraction, amplification and sequencing were performed as previously described (Chiang et al., 2006).

\subsection{Data analyses}

The mtDNA control region sequences of all samples were aligned using Clustal X v1.83 (Thompson et al., 1997) and further edited manually in BioEdit (Hall, 1999). The data set was subjected to the neighbor-joining (NJ) method (Satiou and Nei, 1987) for phylogenetic inference. The NJ tree based on the gamma corrected Tamura-Nei distance matrix was constructed using MEGA Version 3.1 (Kumar et al., 2004). Phylogenetic analysis of three yellowfin tuna (Thunnus albacares) sequences (GenBank accession nos. AF301203, AF301206 and AF301207) was performed to further confirm no sampling error possible. Uncertain samples were excluded from further analyses. The inferred evolutionary model and parameters were used to estimate neighbor-joining (NJ) distances. Robustness of the resulting tree was tested with bootstrapping (Felsenstein, 1985). Two mtDNA control region sequences of bluefin tuna (Thunnus

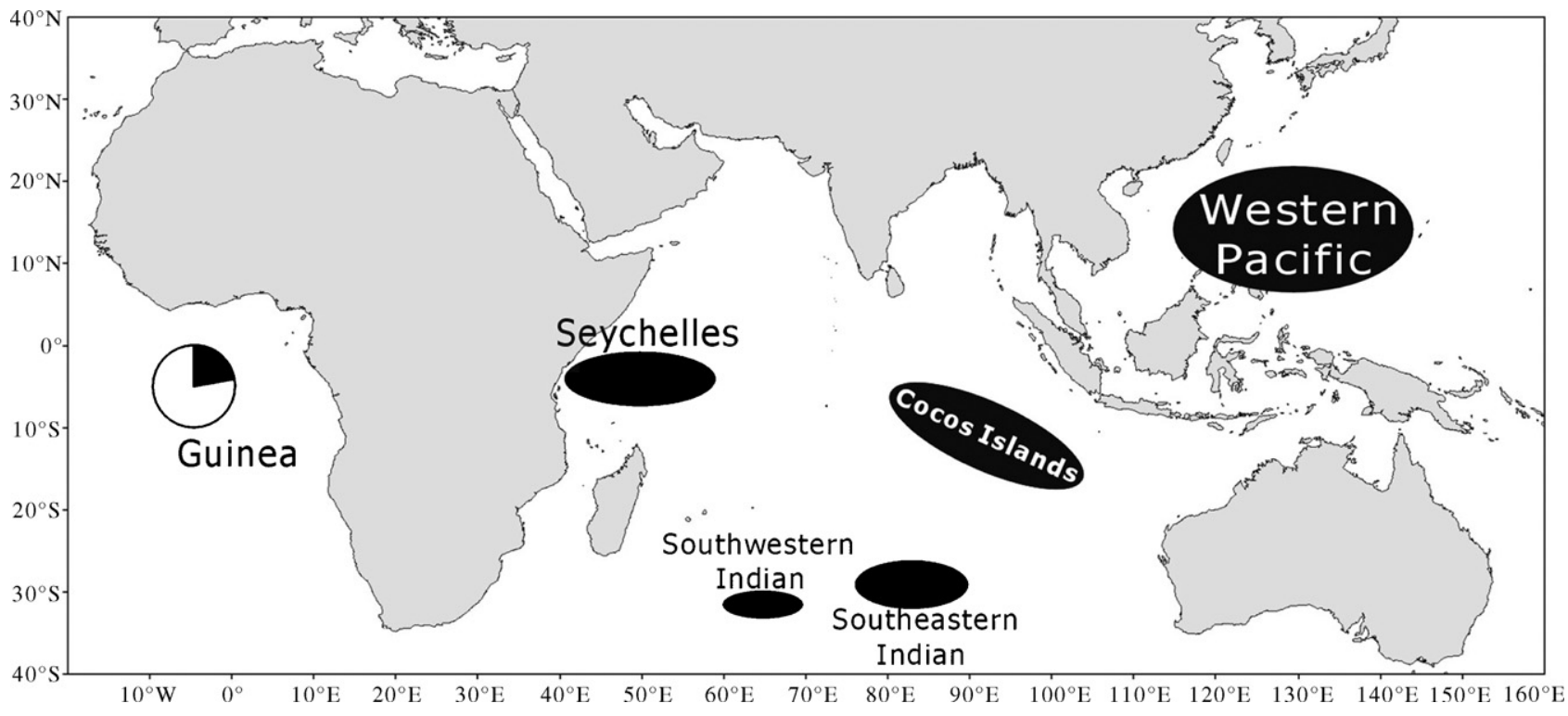

Fig. 1. Map showing the bigeye tuna sampling areas under study. 
thynnus, GenBank accession nos. AF390438 and AF390439) were used as outgroups.

Population genetic analyses were executed using Arlequin 2001 (Schneider et al., 2000), DnaSP 4.0 (Rozas et al., 2003) and MEGA Version 3.1 (Kumar et al., 2004) based on HVR-1 region sequence data. Delineative statistics such as nucleotide composition, number of polymorphic sites $(S)$, haplotypic diversity $\left(H_{\mathrm{d}} ; \mathrm{Nei}, 1987\right)$, nucleotide diversity $(\pi$; Lynch and Crease, $1990)$ and the average number of pairwise nucleotide differences ( $k$; Tajima, 1983) were determined for each geographic population. The inter-haplotype levels of divergence were estimated using the index $\Phi_{\mathrm{ST}}$ (Excoffier et al., 1992), which includes information on mitochondrial haplotype frequency (Weir and Cockerham, 1984) and genetic distances (Tamura-Nei; Tamura and Nei, 1993). Significance of pairwise population comparison was tested by 20,000 permutations. An analysis of molecular variance (AMOVA; Excoffier et al., 1992) was used to examine the amount of genetic variability partitioned within and among populations. Permutation procedures $(n=20,000)$ were used to construct null distributions and to test the significance of variance components for each hierarchical comparison (Guo and Thompson, 1992).

The entire mitochondrial control region data set revealed from the phylogenetic analysis was tested against constant population model and sudden population expansion model using the mismatch distribution (Rogers and Harpending, 1992; Schneider and Excoffier, 1999; Slatkin and Hudson, 1991) as implemented in Arlequin 2001 (Schneider et al., 2000) and DnaSP 4.0 (Rozas et al., 2003). Populations which have been stable over time are predicted to have a more balanced phylogeny shape and a bimodal or multimodal mismatch distribution (Rogers and Harpending, 1992; Schneider and Excoffier, 1999; Slatkin and Hudson, 1991). The fit between the observed and expected distributions was tested using the Harpending's raggedness index (Hri; Harpending, 1994) and sum of squared deviations (SSD) for the estimated stepwise expansion models (Schneider and Excoffier, 1999).

Tajima's $D$ (Tajima, 1989a,b) and Fu's $F_{\mathrm{s}}(\mathrm{Fu}, 1997)$ tests, conducted through Arlequin 2001 (Schneider et al., 2000), were carried out to examine for deviations from neutrality (as would be expected under population expansion). It has been showed that Fu's $F_{\mathrm{S}}$ test outperforms others in detecting population growth for large sample sizes (Ramos-Onsins and Rozas, 2002).

\section{Results}

\subsection{Molecular characteristics}

A fragment of mtDNA control region of approximately 860bp which immediately flanks the $t R N A^{\text {Pro }}$ gene was sequenced in a total of 380 bigeye tuna (T. obesus) individuals including 223, 57 and 100 from the Indian Ocean, Atlantic Ocean and Western Pacific Ocean, respectively. The Western Pacific sequences were previously reported (Chiang et al., 2006). To be concordant with previous studies, the HVR-1 region, a 366-bp sequence at the $5^{\prime}$ end of the mitochondrial control region was analyzed. An overall of 159 variable sites were observed, and 355 haplotypes were defined. Representative sequences have been deposited in Genbank, with Accession nos. AY640289-AY640303 and nos. EF154397-EF154417. A higher A/T base content compared to $C / G$ base content was observed among the sequences examined (mean: $\mathrm{A}=38.2 \%, \mathrm{~T}=27.7 \%, \mathrm{C}=20.2 \%, \mathrm{G}=13.9 \%$ ), which was consistent to previous findings that the D-loop is an $A-T$ rich region of the mitochondrial genome (Brown et al., 1986; Saccone et al., 1987). The total number of polymorphic sites, singleton variable sites and parsimony-informative sites were 159, 38 and 121, respectively. Overall nucleotide diversities (average $\pi=0.046$ ) and haplotypic diversities (average $h=0.99$ ) were both high within each region (Table 1). Provided in Table 1 are all the population genetic statistics.

\subsection{Phylogeny and patterns of population structure}

The phylogenetic analyses using neighbor-joining method with Tamura-Nei distances (with a gamma value of 0.59) revealed three highly divergent clades, with the 2 major clades corresponding to Clades I and II of Alvarado-Bremer et al. (1998) and Martínez et al. (2006), and a recently identified Clade III (Chiang et al., 2006) (Fig. 2). Clade I, loosely supported by a bootstrap value smaller than $50 \%$, was the major clade which contained most specimens in all sampling oceans (Western Pacific $=96 \%$, Cocos Islands $=100 \%$, Southeastern Indian $=100 \%$, Southwestern Indian $=100 \%$, Seychelles $=98 \%$ ) with an exception in Atlantic Ocean (Guinea $=23 \%)$. Even distribution of each sampling area specimens showed no apparent geographic structuring between haplotypes in Clade I. In contrast, Clade II was strongly sup-

Table 1

Descriptive statistics for the studied T. obesus samples

\begin{tabular}{|c|c|c|c|c|c|c|c|c|c|}
\hline Population & Location & Date & $n$ & $H$ & $S$ & $H_{\mathrm{d}}$ & $k$ & $\pi$ & $\theta$ \\
\hline Western Pacific Ocean & $115^{\circ}-144^{\circ} \mathrm{E} ; 7^{\circ}-22^{\circ} \mathrm{N}$ & $\begin{array}{l}\text { May } 2000 \text { to } \\
\text { January } 2003\end{array}$ & 100 & 96 & 104 & $0.999 \pm 0.002$ & $15.4 \pm 6.9$ & $0.043 \pm 0.022$ & $21.4 \pm 5.5$ \\
\hline Cocos Islands & $80^{\circ}-104^{\circ} \mathrm{E} ; 4^{\circ}-18^{\circ} \mathrm{S}$ & August 2004 & 24 & 23 & 62 & $0.996 \pm 0.013$ & $15.3 \pm 7.1$ & $0.043 \pm 0.022$ & $16.6 \pm 5.7$ \\
\hline Southeastern Indian Ocean & $76^{\circ}-90^{\circ} \mathrm{E} ; 27^{\circ}-32^{\circ} \mathrm{S}$ & August 2004 & 32 & 31 & 80 & $0.998 \pm 0.008$ & $15.4 \pm 7.1$ & $0.044 \pm 0.022$ & $20.1 \pm 6.4$ \\
\hline Southwestern Indian Ocean & $60^{\circ}-70^{\circ} \mathrm{E} ; 30^{\circ}-33^{\circ} \mathrm{S}$ & August 2005 & 56 & 48 & 90 & $0.998 \pm 0.003$ & $15.5 \pm 7.0$ & $0.043 \pm 0.021$ & $20.9 \pm 6.0$ \\
\hline Seychelles & $41^{\circ}-60^{\circ} \mathrm{E} ; 1^{\circ}-6^{\circ} \mathrm{S}$ & June 2006 & 111 & 101 & 98 & $0.998 \pm 0.001$ & $15.4 \pm 6.9$ & $0.043 \pm 0.021$ & $19.9 \pm 5.0$ \\
\hline Guinea & $0^{\circ}-10^{\circ} \mathrm{W} ; 0^{\circ}-10^{\circ} \mathrm{S}$ & $\begin{array}{l}\text { May-August } \\
2003\end{array}$ & 57 & 56 & 86 & $0.999 \pm 0.003$ & $22.1 \pm 9.9$ & $0.062 \pm 0.030$ & $19.3 \pm 5.5$ \\
\hline
\end{tabular}

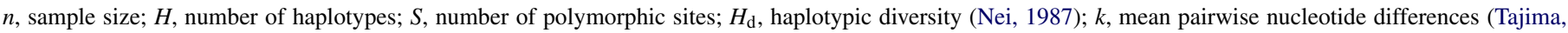
$1983) ; \pi$, nucleotide diversity (Nei, 1987); $\theta$, expected heterozygosity per site (Watterson, 1975) 


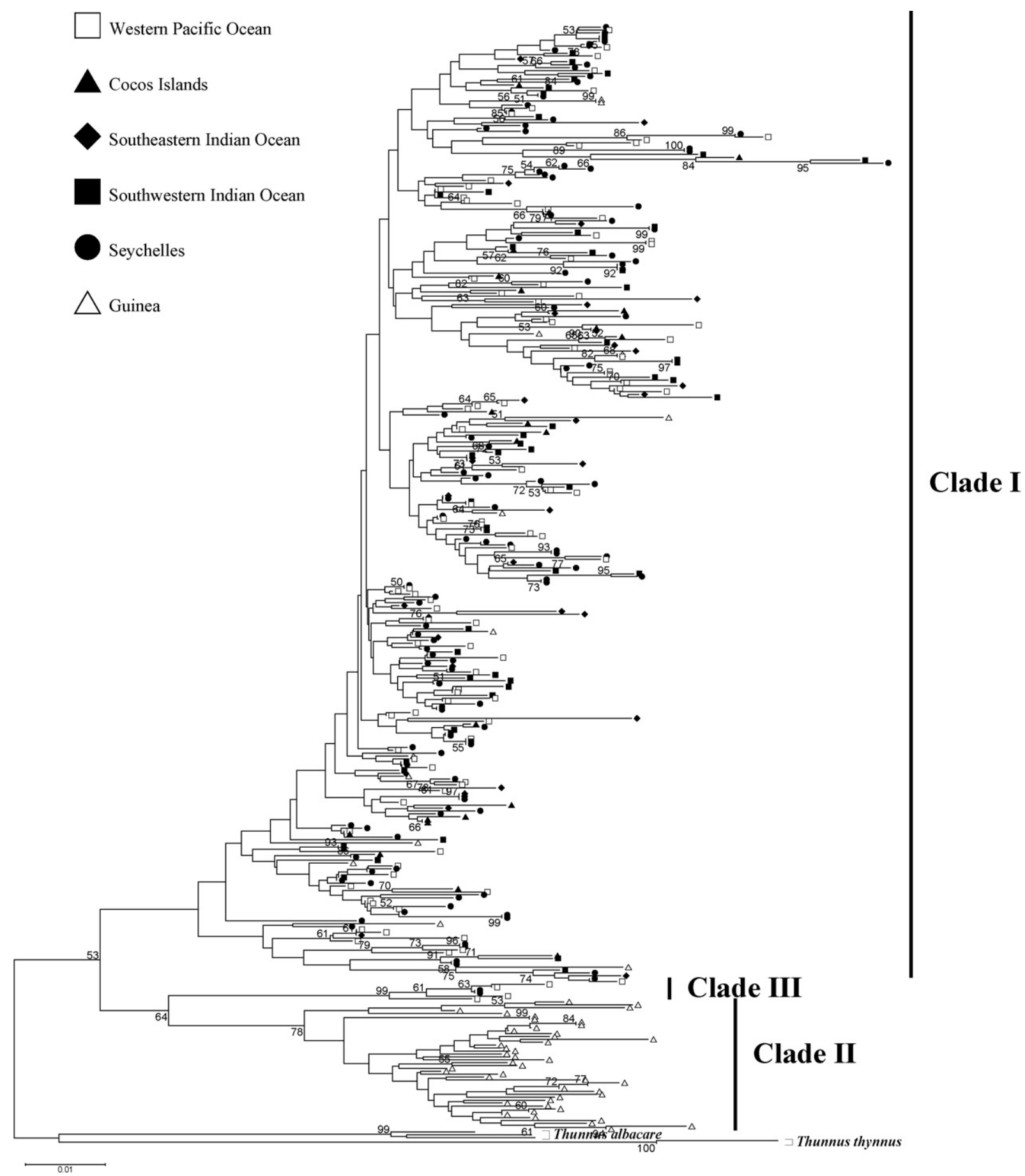

Fig. 2. Neighbor-joining tree estimated with the Tamura and Nei model among mtDNA lineages of bigeye tuna. Haplotypes collected from the Western Pacific, Cocos Islands, Southeastern Indian, Southwestern Indian, Seychelles and Guinea are shown as white squares, black triangles, black rhombus, black squares, black circles and white triangles, respectively. Numbers at nodes indicate the bootstrap values. Only values $>50 \%$ are shown.

ported by a bootstrap value of $78 \%$ and was restricted exclusively to the Atlantic Ocean. It was also the major clade of Atlantic Ocean containing $77 \%$ of its bigeye tuna population. Lastly, Clade III was strongly supported by a bootstrap value of $99 \%$ and was exclusively restricted to the Indian and Western Pacific Oceans with notably fewer haplotypes (Indian $=1 \%$ and Western Pacific $=4 \%$ ). Mean pairwise uncorrected $p$-distances between bigeye tuna and yellowfin tuna was 0.09 , and that between bigeye tuna and bluefin tuna was 0.11 , and those within Clades
I, II and III were 0.04, 0.03 and 0.01, respectively. Mean pairwise uncorrected p-distances between Clades I and II as well as Clades I and III were both 0.08 , and that between Clades II and III was 0.07 .

To obtain results that can be best compared with studies performed by Martínez et al. (2006), we used the Tamura and Nei model to perform hierarchical AMOVA tests and to estimate $\Phi_{\mathrm{ST}}$ values. Genetic structuring between sampling regions was significant $(\Phi=0.20 ; p<0.01)$ (Table 2$)$. AMOVA analyses 
Table 2

Genetic structuring of bigeye tuna populations based on mitochondrial control region sequence data

\begin{tabular}{|c|c|c|c|c|}
\hline \multirow[t]{2}{*}{ Structure tested } & \multicolumn{4}{|c|}{ Observed partition } \\
\hline & Variance & $\%$ total & $\Phi$ statistics & $p$ \\
\hline \multicolumn{5}{|c|}{ (1) One gene pool (Cocos Islands, Southeastern Indian Ocean, Southwestern Indian Ocean, Seychelles, Western Pacific and Guinea) } \\
\hline Among populations & 2.12 & 20.14 & $\Phi_{\mathrm{ST}}=0.20$ & $<0.001$ \\
\hline Within populations & 8.40 & 79.86 & & \\
\hline \multicolumn{5}{|c|}{ (2) One gene pool Clade I (Cocos Islands, Southeastern Indian Ocean, Southwestern Indian Ocean, Seychelles, Western Pacific and Guinea) } \\
\hline Among populations & 0.04 & 0.49 & $\Phi_{\mathrm{ST}}=0.005$ & 0.06 \\
\hline Within populations & 7.90 & 99.51 & & \\
\hline \multicolumn{5}{|c|}{ (3) One gene pool Indian (Cocos Islands, Southeastern Indian Ocean, Southwestern Indian Ocean, and Seychelles) } \\
\hline Among populations & 0.05 & 0.68 & $\Phi_{\mathrm{ST}}=0.007$ & 0.06 \\
\hline Within populations & 7.80 & 99.32 & & \\
\hline
\end{tabular}

Table 3

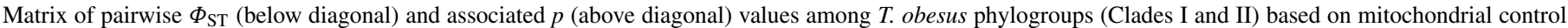
region sequence data

\begin{tabular}{|c|c|c|c|c|c|c|}
\hline Sampling area & $\begin{array}{l}\text { Western Pacific } \\
\text { Ocean }\end{array}$ & Cocos Islands & $\begin{array}{l}\text { Southeastern } \\
\text { Indian Ocean }\end{array}$ & $\begin{array}{l}\text { Southwestern } \\
\text { Indian Ocean }\end{array}$ & Seychelles & Guinea (I/II) \\
\hline Western Pacific Ocean & - & 0.31 & 0.25 & 0.15 & 0.73 & $0.12 /<0.001$ \\
\hline Cocos Islands & 0.002 & - & 0.07 & 0.15 & 0.31 & $0.17 /<0.001$ \\
\hline Southeastern Indian Ocean & 0.003 & 0.016 & - & 0.34 & 0.03 & $0.32 /<0.001$ \\
\hline Southwestern Indian Ocean & 0.004 & 0.009 & 0.002 & - & 0.17 & $0.06 /<0.001$ \\
\hline Seychelles & 0.002 & 0.003 & 0.015 & 0.004 & - & $0.08 /<0.001$ \\
\hline Guinea (I/II) & $0.017 / 0.586^{*}$ & $0.015 / 0.601^{*}$ & $0.005 / 0.615^{*}$ & $0.026 / 0.609^{*}$ & $0.021 / 0.590^{*}$ & $<0.001$ \\
\hline
\end{tabular}

\footnotetext{
* Significant values at $p<0.01$.
}

also revealed no structure within the global Clade I specimens and within the Indian Ocean specimens $(\Phi=0.005 ; p=0.06$; $\Phi=0.007 ; p=0.06$, respectively). Pairwise $\Phi_{\mathrm{ST}}$ comparisons between the Western Pacific and each regional population of the Indian Ocean were not significant (Table 3). Clade I in the Atlantic Ocean population showed no significant differentiation when compared with those of the Western Pacific and the Indian Ocean. On the other hand, Clade II of the Atlantic Ocean showed significant differentiation when compared with clades of the Pacific and the Indian Ocean.

\subsection{Demographic patterns}

Listed in Table 4 were the results of neutrality tests and demographic parameters of bigeye tuna's entire HVR-1 data set and their phylogroups. Bimodal distribution between Clades I and II was revealed by mismatch analyses. When analyzed separately, unimodal distributions were observed in both Clades (figure not shown). These results were of non-significant differences as that predicted by the growth expansion model (measured by the sum of squared deviation; $p>0.05$ ). The Harpending's raggedness indices $(\mathrm{Hri})$ were low, indicating a significant fit between the observed and the expected distributions, and therefore further evidencing population expansion (Harpending, 1994). The mismatch analyses allowed estimation of effective female population size, as well as the time and rate of expansion (Harpending, 1994). Estimated effective female population size after expan$\operatorname{sion}\left(\theta_{1}=96.797,141.309\right.$ and 4682.500$)$ was about 30,60 and 2665 times higher than before expansion $\left(\theta_{0}=3.183,2.333\right.$ and
Table 4

Statistical tests of neutrality, and demographic parameters estimates for T. obesus entire mitochondrial control region data set, and phylogroups (Clades I and II)

\begin{tabular}{|c|c|c|c|c|}
\hline & All samples & Clade I & Clade II & Clade III \\
\hline \multicolumn{5}{|c|}{ Goodness of fit tests } \\
\hline Tajima, $D$ & -1.37 & -1.61 & -1.04 & -0.33 \\
\hline Fu's, $F_{\mathrm{s}}$ & $-634.18^{*}$ & $-555.47^{*}$ & $-33.48^{*}$ & 0.12 \\
\hline \multicolumn{5}{|c|}{ Demographic parameters } \\
\hline $\mathrm{Hri}$ & 19.910 & 0.001 & 0.005 & 0.444 \\
\hline$S S D$ & 0.0014 & 0.0007 & 0.0013 & 0.1975 \\
\hline$S$ & 142 & 141 & 64 & 15 \\
\hline$\theta_{0}$ & 5.331 & 2.655 & 2.372 & 1.757 \\
\hline$\theta_{1}$ & 166.953 & 96.797 & 141.309 & 4682.500 \\
\hline$\tau$ & 9.489 & 9.425 & 8.768 & 3.043 \\
\hline
\end{tabular}

* Significant values at $p<0.05$.

1.757) for Clades I, II and III, respectively. Additionally, Fu's $F_{\mathrm{S}}$ statistic indicated a significant departure from neutrality (excess of low-frequency haplotypes) in the sequence data of Clades I and II, as may be expected when a population is under selection or expansion. The more conservative Tajima's test indicated negative but non-significant deviations from neutrality for both Clades I and II.

\section{Discussion}

The DNA sequence analysis assay is particularly useful for population studies of animal species with worldwide geographic distributions (e.g., bigeye tuna) that make complete sampling 
very difficult. There have been four mtDNA genetic analyses carried out by the PCR-RFLP method on the bigeye tuna population structure (Alvarado-Bremer et al., 1998; Chow et al., 2000; Appleyard et al., 2002; Durand et al., 2005). It is a single nucleotide polymorphism assay of a limited number of restriction nucleotide mutation sites. Recently, a study conducted by Martínez et al. (2006) used PCR-sequencing for the first time to analyze the bigeye tuna population structure of the Atlantic Ocean. Despite the methods used, all these studies showed that the bigeye tuna population structure of Atlantic were built up by two clades, Clades I and II. In contrast to results obtained by previous RFLP studies in which trace amount of Clade II population was also observed in the Indo-Pacific Ocean, data from Martínez et al. (2006) has led these authors to conclude that Clade II is exclusively restricted to the Atlantic Ocean. Since their study only included 47 samples from Seychelles, to further verify that Indo-Pacific Ocean does not contain Clade II, we performed PCR-sequencing analyses on 223 additional samples from different regions of the Indian Ocean and 100 samples from the Western Pacific Ocean, as well as 57 samples from the Atlantic Oceans.

This study showed high levels of both the haplotype and nucleotide diversities (Table 1), similar to those reported for other highly migratory pelagic fishes (Alvarado-Bremer et al., 1997, 2005; Grant and Bowen, 1998; Carlsson et al., 2004; Ely et al., 2005; Martínez et al., 2006). In addition, bigeye tuna nucleotide diversity of the Guinea population (about 0.06) was higher than that of other regional populations (about 0.04 ). This may be due to the high mutation rate of HVR-1 which elevates within population diversity levels for this marker. However, the data did show consistency with our results from the NJ tree, indicating the presence of two clades within the Atlantic Ocean. Several characteristics such as large population sizes, environmental heterogeneity, and life-history traits which favor rapid population increase could be used to explain the maintenance of high haplotypic diversity within populations (Nei, 1987; Avise, 1998). As the bigeye tuna population is generally large and widely distributed throughout the world, we propose this may account for the high level of haplotypic diversity observed in this study.

It has been reported that genetic differentiation is generally low among tuna populations within and between oceans (Alvarado-Bremer et al., 1998; Grewe and Hampton, 1998; Chow et al., 2000; Appleyard et al., 2002; Durand et al., 2005; Ely et al., 2005). For example, population genetic studies on mtDNA of Pacific yellowfin revealed very low levels of genetic differentiation (Scoles and Graves, 1993; Ward et al., 1994, 1997; Appleyard et al., 2001; Ely et al., 2005). In this study, no genetic differentiation was detected within the Indian Ocean and between the Indian Ocean and Western Pacific Ocean (Table 3; Chiang et al., 2006). This lack of genetic structure demonstrated extensive gene flow within the Indo-Pacific Ocean.

The NJ phylogeny showed that the bigeye tuna populations of the Indian, Western Pacific and Atlantic Oceans were grouped into three distinct phylogroups, Clades I, II and III. This confirmed the existence of two mitochondrial clades (Clades I and II) throughout the Atlantic Ocean as previously suggested
(Alvarado-Bremer et al., 1998; Chow et al., 2000; Martínez et al., 2006). Previous studies involving RFLP analyses revealed that few haplotypes from the Indo-Pacific Ocean fell into the Clade II phylogroup (Alvarado-Bremer et al., 1998; Appleyard et al., 2002; Chow et al., 2000). However, in agreement with the study of Martínez et al. (2006), our reconstructed NJ tree (including 323 Indian and Western Pacific samples) confirmed that Clade II was exclusively restricted to the Atlantic Ocean. In addition, a new phylogroup, Clade III, including four and two individuals was found in the Western Pacific and Seychelles, respectively. To further investigate the distribution of Clade III among the Oceans, we added 331 bigeye tuna sequences of Martínez et al. (2006) from Genbank (Accession Nos. DQ126342-DQ126676) to ours for phylogenetic relationship analyses (data not shown). The results indicated that Clade III was exclusively restricted to the Indian and Western Pacific Oceans while Clade II is exclusively limited to the Atlantic Ocean.

With samples taken from additional regions of the Indian Ocean, our mitochondrial evidence of no population structuring in the Indian Ocean was concordant with nuclear evidence based on microsatellite data (Appleyard et al., 2002). AMOVA tests and pairwise $\Phi_{\mathrm{ST}}$ comparisons both supported a single stock of bigeye tuna in the Indian Ocean, given that the existence of two clades (Clades I and III) was considered. Furthermore, no significant differentiation was observed between populations of the Western Pacific Ocean, Indian Ocean and Clade I of Guinea. This may be due to possible unidirectional gene flow from the Western Pacific Ocean through the Indian Ocean to the Atlantic Ocean (Durand et al., 2005). In contrast, significant differentiation was observed between populations of the Western Pacific Ocean, Indian Ocean and Clade II of Guinea.

It has been proposed that marine fishes can be classified into four categories based on different combinations of small and large values of haplotype diversity $(h)$ and nucleotide diversity $(\pi)$ of mtDNA sequences (Grant and Bowen, 1998). Our study of the Indian Ocean bigeye tuna revealed large values of both $h$ and $\pi$ (Table 1 ), which were used to characterize the fourth category of marine fishes by Grant and Bowen (1998). The high level of divergence is attributed to a long evolutionary history in a large stable population or to a secondary contact between previously differentiated allopatric lineages. To decide which explanation best describes the bigeye tuna phylogroups, the sequence data were further tested by Tajima's and Fu's $F_{\mathrm{s}}$ statistical tests. Significant negative Fu's $F_{\mathrm{s}}$ value and negative Tajima's value for Clades I and II in this study indicated the presence of population expansion. Both non-significant values of Tajima's $D$ and Fu's $F_{\mathrm{s}}$ for Clade III suggested that the population was under equilibrium. Mismatch distribution analysis further supported this conclusion with a unimodal pattern for each of Clades I and II and with multimodal peaks for Clade III. Based on the data we have collected, which were consistent with previous suggestions proposed by Martínez et al. (2006), secondary contacts between previously differentiated allopatric lineages appeared to be a more possible explanation in this scenario. According to Martínez et al. (2006), it appears that Clades I and II may have been isolated during the Pleistocene glacial maxima due to the reduction of tropical marine habitats. Through time, Clade 
II eventually became the dominant population in the Atlantic Ocean and Clade I in the Indo-Pacific Ocean.

The results of this study indicated that the Indian Ocean bigeye tuna constituted a single panmictic population and thus supported its current management policy as a single stock in this ocean. In addition, our results showed the restriction of Clades II and III at the Atlantic Ocean and the Indo-Pacific Ocean, respectively. Due to the fact that Atlantic bigeye tuna were mis-reported to the market as Indian Ocean ones to avoid quota management, and that this issue has been intensively discussed in recent years (Annex 10 of ICCAT, 2006), our data could be useful in identifying the source of fish products when dealing with mis-reporting issues.

\section{Acknowledgments}

We would like to thank Dr. Chaolun Allen Chen for his helpful comments. The funding for this work is provided by the Fisheries Agency, Council of Agriculture, Executive Yuan, Taiwan, ROC (grant no. 95AS-14.1.2-FA-F1) and National Science Council, Taiwan, ROC (grant no. 95-2611-M-002-013).

\section{References}

Alvarado-Bremer, J.R., Naseri, I., Ely, B., 1997. Orthodox and unorthodox phylogenetic relationships among tunas revealed by the nucleotide sequence analysis of the mitochondrial DNA control region. J. Fish Biol. 50, 540-554.

Alvarado-Bremer, J.R., Stequert, B., Robertson, N.W., Ely, B., 1998. Genetic evidence for inter-oceanic subdivision of bigeye tuna (Thunnus obesus Lowe) populations. Mar. Biol. 132, 547-557.

Alvarado-Bremer, J.R., Vinas, J., Mejutoc, J., Ely, B., Pla, C., 2005. Comparative phylogeography of Atlantic bluefin tuna and swordfish: the combined effects of vicariance, secondary contact, introgression, and population expansion on the regional phylogenies of two highly migratory pelagic fishes. Mol. Phyl. Evol. 36, 169-187.

Appleyard, S.A., Grewe, P.M., Innes, B.H., Ward, R.D., 2001. Population structure of yellowfin tuna (Thunnus albacares) in the western Pacific Ocean, inferred from microsatellite loci. Mar. Biol. 139, 383-393.

Appleyard, S.A., Ward, R.D., Grewe, P.M., 2002. Genetic stock structure of bigeye tuna in the Indian Ocean using mitochondrial DNA and microsatellites. J. Fish Biol. 60, 767-770.

Avise, J., 1998. Phylogeography. Mass: Harvard University Press, Cambridge.

Brown, G.G., Gadaleta, G., Pepe, G., Saccone, C., Sbisa, E., 1986. Structural conservation and variation in the D-loop-containing region of vertebrate mitochondrial DNA. J. Mol. Biol. 192, 503-511.

Buonnacorsi, V.P., McDowell, J.R., Graves, J.E., 2001. Reconciling patterns of inter-ocean molecular variance from four classes of molecular markers in blue marlin (Makaira nigricans). Mol. Ecol. 10, 1179-1196.

Carlsson, J., McDowell, J.R., Diaz-Jaimes, P., Carlsson, J.E., Boles, S.B., Gold, J.R., Graves, J.E., 2004. Microsatellite and mitochondrial DNA analyses of Atlantic bluefin tuna (Thunnus thynnus thynnus) population structure in the Mediterranean Sea. Mol. Ecol. 13, 3345-3356.

Chiang, H.C., Hsu, C.C., Lin, H.D., Ma, G.C., Chiang, T.Y., Yang, H.Y., 2006. Population structure of bigeye tuna (Thunnus obesus) in the South China Sea, Philippine Sea and western Pacific Ocean inferred from mitochondrial DNA. Fish. Res. 79, 219-225.

Chow, S., Okamoto, H., Miyabe, N., Hiramatsu, K., Barut, N., 2000. Genetic divergence between Atlantic and Indo-Pacific stocks of bigeye tuna (Thunnus obesus) and admixture around South Africa. Mol. Ecol. 9, 221-227.

Durand, J.D., Collet, A., Chow, S., Guinand, B., Borsa, P., 2005. Nuclear and mitochondrial DNA markers indicate unidirectional gene flow of IndoPacific to Atlantic bigeye tuna (Thunnus obesus) populations, and their admixture off southern Africa. Mar. Biol. 147, 313-322.
Ely, B., Vinas, J., Alvarado Bremer, J.R., Black, D., Lucas, L., Covello, K., Labrie, A.V., Thelen, E., 2005. Consequences of the historical demography on the global population structure of two highly migratory cosmopolitan marine fishes: the yellowfin tuna (Thunnus albacares) and the skipjack tuna (Katsuwonus pelamis). BMC Evol. Biol. 5, 19.

Excoffier, L., Smouse, P.E., Quattro, J.M., 1992. Analysis of molecular variance inferred from metric distances among DNA haplotypes: application to human mitochondrial DNA restriction data. Genetics 131, 479-491.

Felsenstein, J., 1985. Confidence limits on phylogenies: an approach using bootstrap. Evolution 39, 783-791.

Fu, Y.X., 1997. Statistical tests of neutrality of mutations against population growth, hitchhiking and background selection. Genetics 147, 915-925.

Grant, W.S., Bowen, B.W., 1998. Population histories in deep evolutionary lineages of marine fishes: insights from sardines and anchovies and lessons for conservation. J. Hered. 89, 415-426.

Grewe, P.M., Hampton, J., 1998. An assessment of bigeye (Thunnus obesus) population structure in the Pacific Ocean based on mitochondrial DNA and DNA microsatellite analysis. SOEST Publication 98-05, JIMAR Contribution 98-320.

Guo, S., Thompson, E., 1992. Performing the exact test of Hardy-Weinberg proportion for multiple alleles. Biometrics 48, 361-372.

Hall, T.A., 1999. BioEdit: a user-friendly biological sequence alignment editor and analysis program for Windows 95/98/NT. Nucl. Acids Symp. Ser. 41, 95-98.

Harpending, R.C., 1994. Signature of ancient population growth in a lowresolution mitochondrial DNA mismatch distribution. Hum. Biol. 66, 591-600.

ICCAT, 2005. Report of the Second World Meeting on Bigeye Tuna. Madrid, Spain, March 10-13, 2004. Col. Vol. Sci. Pap. ICCAT, 57, 2, 3-38.

ICCAT, 2006. Report for the Biennial Period, 2004-2005, Part II (2005), vol. 1. International Commission for the Conservation of Atlantic Tunas, Madrid, Spain.

Kumar, S., Tamura, K., Nei, M., 2004. MEGA3: integrated software for molecular evolutionary genetics analysis and sequence alignment. Brief. Bioinform. $5,150-163$.

Lynch, M., Crease, T.J., 1990. The analysis of population survey data on DNA sequence variation. Mol. Biol. Evol. 7, 337-394.

Martínez, P., Gonzalez, E.G., Castilho, R., Zardoya, R., 2006. Genetic diversity and historical demography of Atlantic bigeye tuna (Thunnus obesus). Mol. Phyl. Evol. 39, 404-416.

Nei, M., 1987. Molecular Evolutionary Genetics. Columbia University Press, New York.

Ramos-Onsins, S.E., Rozas, J., 2002. Statistical properties of new neutrality tests against population growth. Mol. Biol. Evol. 19, 2092-2100.

Rogers, A.R., Harpending, H., 1992. Population growth makes waves in the distribution of pairwise genetic differences. Mol. Biol. Evol. 9, $552-569$.

Rozas, J., Sanchez-DeI Barrio, J.C., Messeguer, X., Rozas, R., 2003. DnaSP, DNA polymorphism analyses by the coalescent and other methods. Bioinformatics 19, 2496-2497.

Saccone, C., Attimonelli, M., Sbisa, E., 1987. Structural elements highly preserved during the evolution of the D-loop containing region in vertebrate mitochondrial DNA. J. Mol. Evol. 26, 205-211.

Satiou, N., Nei, M., 1987. The neighbor-joining method: a new method for reconstructing phylogenetic tree. Mol. Biol. Evol. 4, 406-425.

Schneider, S., Excoffier, L., 1999. Estimation of past demographic parameters from the distribution of pairwise differences when the mutation rates vary among sites: application to human mitochondrial DNA. Genetics 152, 1079-1089.

Schneider, S., Roessli, D., Excoffier, L., 2000. ARLEQUIN, Version 2.000: A Software for Population Genetics Data Analysis. University of Geneva, Switzerland.

Scoles, D.R., Graves, J.E., 1993. Genetic analysis of the population structure of yellowfin tuna, Thunnus albacares, from the Pacific Ocean. Fish. Bull. (Washington, DC) 91, 690-698.

Slatkin, M., Hudson, R.R., 1991. Pairwise comparisons of mitochondrial DNA sequences in stable and exponentially growing populations. Genetics 129, $555-562$. 
Tajima, F., 1983. Evolutionary relationship of DNA sequences in finite populations. Genetics 105, 460-467.

Tajima, F., 1989a. The effect of change in population size on DNA polymorphism. Genetics 123, 597-601.

Tajima, F., 1989b. Statistical method for testing the neutral mutation hypothesis by DNA polymorphism. Genetics 123, 585-595.

Tamura, K., Nei, M., 1993. Estimation of the number of nucleotide substitutions in the control region of mitochondrial DNA in humans and chimpanzees. Mol. Biol. Evol. 10, 512-526.

Thompson, J.D., Gibson, T.J., Plewniak, F., Jeanmougin, F., Higgins, D.G., 1997. The CLUSTALX windows interface: flexible strategies for multiple sequence alignment aided by quality analysis tools. Nucl. Acids Res. 25, 4876-4882.
Watterson, G., 1975. On the number of segregating sites in genetical models without recombination. Theor. Popul. Biol. 7, 256-276.

Ward, R.D., Elliott, N.G., Grewe, P.M., Smolenski, A.J., 1994. Allozyme and mitochondrial DNA variation in yellowfin tuna (Thunnus albacares) from the Pacific Ocean. Mar. Biol. 118, 531-539.

Ward, R.D., Elliott, N.G., Innes, B.H., Smolenski, A.J., Grewe, P.M., 1997. Global population structure of yellowfin tuna Thunnus albacares, inferred from allozyme and mitochondrial DNA variation. Fish. Bull. (Washington, DC) $95,566-575$.

Weir, B.S., Cockerham, C.C., 1984. Estimating $F$-statistics for the analysis of population structure. Evolution 38, 1358-1370. 